the only reasonable course, as the Local Government Boundary Commission recognized; but apart from the ef ect of the decay of the minor local authorities when resources are too limited for them to form efficient units for modern services, the claims of many large towns for boundary extensions cannot in equity be longer ignored. Debates in the last Parliament demonstrated the alarm with which the situation was regarded by members of all parties. Mr. Harold Macmillan's statement in the House of Commons that he hoped to present some measure of local government reform in the course of the present Parliament will be warmly welcomed. He insisted, however, that without substantial agreement between the interests concerned there is no prospect of introducing such a measure even in 1953. A determined attempt to reach agreement on the subject is worth making at the present time. If it succeeded, it would be of real national benefit, and its short-term effects might even ease the present strain on man-power to some extent, apart altogether from the long-term effects on the vitality of democratic institutions.

\section{ADVANCES IN PLANT PHYSIOLOGY}

Annual Review of Plant Physiology

Daniel I. Arnon (editor), Leonard Machlis (associate editor). Vol. 2. Pp. $x+361$. (Stanford, Calif. : Annual Reviews, Inc., 1951.) 6 dollars.

A $\mathrm{N}$ examination of the present volume raises the -1 question as to what are the aims of such a publication. The preface to the series appearing in the first volume mentions "knitting closer ties between physiologists active in agricultural specialties and those engaged in fundamental research" ; "service in teaching at advanced level"; and "critical evaluation of results rather than encyclopedic completeness".

In this volume there are nearly nineteen hundred literature citations - an average of nearly six per page of text. The longest article has the lowest average of a little more than two while the shortest has the highest of about twenty-four per page. Has the question of the necessity of all these citations been considered ? It would be invidious to pick out particular contributors; but some passages are little more than catalogues of publications.

While some of the articles might well be of service for teaching at an advanced level and might have meaning for the authors of other articles in this volume, others can mean little to any but the extreme specialist. A specialist on photosynthesis can easily grasp the contents of the article on experimental morphogenesis in vascular plants and sce that many physiological problems arise; but are there physiologists, except those who have kept up to date in the subject, who would gain much light from the articles on the kinetics and chemistry of photosynthesis and on the physical background of photosynthesis? It is doubtful if one "active in agricultural specialties" would find time to acquire the background of knowledge to appreciate such articles. To say this is not to pass judgment on the articles, but to raise the question as to whether a volume in this series is the right place for such reviews. One danger of such articles written by persons of great authority in special fields is that they may mislead the uninitiated when they refer to other matters. To add to Warburg's laurels by stating that his work of 1919 was "pioneer work in this field" of "the influence of external conditions on photosynthetic rate" is to give less credit than Warburg himself gave to the real pioneers.

Limitations of space and competence of the reviewer make it impossible to give an appraisal of each of the thirteen contributions; but some of the chapters, because of their exceptional nature, call for special comment. The inclusion of an article on a topic such as experimental morphogenesis in a review of plant physiology is welcomed. It directs the attention of the physiologist to problems awaiting solution and should remind him that plant physiology is a branch of botanical biology. The article on permeability, apart from a few references to yeast, makes only one reference to plants. The possibility that vacuolated plant cells may pose quite different problems from those faced by students of muscle and nerve might have been considered in an article in a book on plant physiology. This article finishes on a philosophical level, for it says "this point of view is more interesting to the physiologist since a substance entering the cell through a hole seems quite uninspiring". One wonders whether a physicist would be inspired.

This volume gives the impression of being the unco-ordinated efforts of a team of experts, some of them writing with the editorial aims in mind and others writing for their fellow experts and at times. falling to the level of a briefly annotated catalogue.

G. E. BRIGGS

\section{THE RIEMANN ZETA-FUNCTION}

\section{The Theory of the Riemann Zeta-Function}

By Prof. E. C. Titchmarsh. Pp. vii+346. (Oxford : Clarendon Press ; London: Oxford University Press, 1951.) 40s, net.

DROF. E. C. 'il'LCHMARSH'S well-known tract on the Riemann zeta-function was written some twenty years ago. It is now out of print and, according to its author, out of date: the present book has been written to replace it. How then has the situation changed in the meantime? Not a great deal. The twenty-year period 1910-30 had been the heroic age in the theory of the zeta-function. Hardy had proved that an infinity of zeros lie on the critical line and, with Littlewood, had improved this to $N(T)>A T$. The same authors had found the approximate functional equation and the square mean value theorem which follows from it. Ingham and Titchmarsh had found mean value theorems of the fourth and higher orders. Weyl, Hardy and Littlewood and Van der Corput had discovered ways of dealing with exponential sums, and Bohr, Landau and others had brought Dirichlet's and Kronecker's theorems to bear. But each fresh discovery seemed at the same time to disclose new difficulties which made the goal seem even farther away. The better the behaviour of the zeta-function was understood, the more hopeless did it appear to understand it completely, and there seemed to be a danger that the advance would get bogged down in a morass of exponential sums. 